\title{
Effect of humic substances and clay minerals on the hydrosorption capacity of clay particles in meadow soils (Middle Priamurje, Far East of Russia)
}

\author{
Lira A. Matiushkina and Galina V. Kharitonova*
}

\begin{abstract}
Background: The study of clay fractions is usually focused on water-dispersible clay (WDC), which is a good indicator of many soil processes involving water (water erosion, transfer and removal of nutrients and contaminants). Aggregated clay (AC) that remains after WDC extraction is also important, as it controls the formation of aggregates and their mechanical and water resistance. The aim of this study was a gradual extraction of WDC and AC fractions from periodically overmoistening meadow podbel (mollic planosol) and the study of the content and composition of humic substances and clay minerals in these fractions as well as their effect on the hydrosorption capacity.

Results: The complete extraction of clay fractions showed that AC prevails over WDC along the entire profile and most evidently in the Ag horizon. Most of the organic matter is concentrated in AC. X-ray diffractometry and SEM analysis revealed a similar set of minerals in both fractions, but in different proportions. In the Ag and Elcg horizons, WDC is enriched with clastic components (fine-dispersed quartz, feldspars, amphiboles) and clay minerals with rigid structures (illite, kaolinite, chlorite), compared to AC. In the Btg1 horizon smectite prevails in both fractions. The specific surface, which characterizes the hydrosorption capacity of clays, of WDC is $28-95 \mathrm{~m}^{2} / \mathrm{g}$ less than that of AC. Maximal difference in specific surface of clays is found in the horizon Elcg, where AC has the highest content of free iron.

Conclusions: The present study allowed defining the heterogeneity of the total clay in the periodically overmoistened meadow soil, which is manifested in differences in composition and properties of WDC and AC fractions. AC largely determines hydrosorption properties of soil due to a high content of organic matter and the predominance of swelling minerals in its composition, compared with WDC. The obtained data highlight the importance of studying clay fractions WDC and AC for the characteristics of differentiation and aggregation of the clay in soils.
\end{abstract}

Keywords: Meadow podbel, Water-dispersible clay, Aggregated clay, Specific surface, Clay minerals, Humic substances

\section{Background}

Humic substances (HS) and clay minerals, concentrated in clay fractions, are important factors for the formation of aggregate and pore structure of soil. They also determine the amount of moisture adsorbed/desorbed by soil from the surrounding space and its dynamics $[1,2]$.

*Correspondence: gkharitonova@mail.ru

Institute of Water and Ecology Problems, Far Eastern Branch, Russian

Academy of Sciences, 56 Dikopoltsev St, 680000 Khabarovsk, Russia
It was found out that in different soil types, the amount of adsorbed water and the value of the main parameter of the equation of the water vapor adsorption isotherm (Wmg-maximal hydroscopic moisture) are determined by the total content of clay and its mineralogical composition $[3,4]$. In terms of perceptions of the soil matrix organization, the composition and surface of fine soil minerals form a mineral matrix, which affects all soil processes, including the distribution of humic substances by certain "local adsorption centers". Humic substances

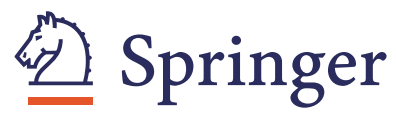

(c) 2015 Matiushkina and Kharitonova. This article is distributed under the terms of the Creative Commons Attribution 4.0 International License (http://creativecommons.org/licenses/by/4.0/), which permits unrestricted use, distribution, and reproduction in any medium, provided you give appropriate credit to the original author(s) and the source, provide a link to the Creative Commons license, and indicate if changes were made. The Creative Commons Public Domain Dedication waiver (http://creativecommons.org/publicdomain/zero/1.0/) applies to the data made available in this article, unless otherwise stated. 
promote the aggregation and stability of soil to a greater extent than clay minerals. The reason is their amphiphilic and hydrophilic-hydrophobic properties. The specific surface of the organic matrix is determined by the surface of the mineral matrix, and the latter in turn depends on the content of fine particles (mostly $<2 \mu \mathrm{m}$ ) [5-7].

At present, in addition to the total clay, the water-dispersible clay (WDC) fraction is studied. The content and properties of WDC and their relationships with various soil physical, chemical and mineralogical properties have been examined in a number of studies. WDC characteristics are used to evaluate soil aggregation stability, erosion resistance of soil to wind and water effects, the risk of surface sealing and crusting under drying up, and the loss of nutrients and contaminants in the soil profile [8-16].

Under periodical overmoistening of meadow podbels, WDC particles are easily mobilized by water and possibly participate in the suspension transfer down the soil profile. This assists the profile differentiation by the substance composition. In case of many clayey soils of humid regions, this peculiarity has a negative effect. When the content of WDC is high, the colmatage of agricultural drains takes place and the "crust" is formed on the drying surface of cultivated soils. Therefore, clayey soils of a humid zone require monitoring and special agricultural technologies to reduce the soil capacity for dispergation in contact with water.

In our opinion, aggregated clay $(\mathrm{AC})$ that remains after WDC extraction is also important, as it controls the formation of aggregates and their mechanical and water resistance [17].

The aim of this study was a gradual extraction of WDC and $\mathrm{AC}$ fractions from soil and the study of the content and composition of humic substances and clay minerals in these fractions as well as their effect on the hydrosorption capacity. This approach is important not only for periodically overmoistened meadow soils in the Amur River valley in the south of the Russian Far East, but for most clayey soils of the humid zone.

\section{Materials}

The investigated soil profile is located on the flat part of the second above-floodplain terrace of the Amur River in the south-western part of the Middle-Amur Lowland, $150 \mathrm{~km}$ to the south of the City of Birobidzhan (Fig. 1). The soil-forming rock is loamy clay deposits of lake-alluvial origin. The vegetation is mostly a motley grass-sedge meadow. The climate is a combination of moderately continental and monsoon features. The average annual temperature is $0.6-1.1{ }^{\circ} \mathrm{C}$; the average annual precipitation is $500-600 \mathrm{~mm}$. Snow melting in spring and heavy summer rains creates conditions of temporary excessive soil surface moistening. According to the Russian national soil classification [18], the studied soil is included in the section of texture-differentiated soils, the type of darkhumic gleyic podbels with horizon sequences $\mathrm{AO}-\mathrm{Ag}-$ AElcg-Elcg-ElBtg-Btg1-Btg2-(BC)g-Cg. According to the WRB $[19,20]$, it corresponds to the planosol order. Detailed classification is mollic planosol (pedomorphic, redoxic, with illite dominant). In the Russian Far East south meadow podbels are used to grow crops only after the drainage amelioration.

The humic Ag horizon (color moist 10YR 3/4) is $10-15 \mathrm{~cm}$ thick. In the upper part, it is densely covered with the roots of meadow vegetation; its lower boundary is irregular, which is characteristic of lowland meadow soils. The transition to the packed grayish AElcg horizon (10 YR 4/3) is gradual. The eluvial Elcg horizon (10YR 5/4) is $20-30 \mathrm{~cm}$ thick. Oxidation microzones of intensely ocher shade (10Y $5 / 8)$ contain multiple manganese-ferrous concretions (1-2 $\mathrm{mm}$ in diameter).

The illuvial Btg1 horizon at a depth of 50(65)-70(80) cm is of non-uniform color (the basic background is $10 \mathrm{YR}$ 4/4, with abundance of mottles 10YR 7/6) with very strong grain aggregates covered by grayish black cutans. Compact manganese-ferrous concretions $2-3 \mathrm{~mm}$ in diameter can be found here. The lower part of the illuvial Btg2 horizon has a compact nutty structure. Angular-nut aggregates (peds of the first order) are covered with a greyish cutan outside and are ferritized inside. The lower part of the profile [the (BC)g horizon, $120-140 \mathrm{~cm}$ ], is characterized by nutty structure, multiple whitish stains, veins, and black manganese patches. A special morphological characteristic of Btg2 and (BC)g horizons is the presence of a bleached fine-dispersed substance on the facets of structural units in the form of local clusters. WDC and AC subfractions of clay were extracted from the three main genetic horizons of the studied soil: the humic Ag, eluvial Elcg and illuvial Btg1 horizons.

The general characteristics of physical and chemical properties of the main horizons of the studied soil profile are given in Table 1.

\section{Methods}

WDC and AC fractions (particle size $<2 \mu \mathrm{m}$ ) were identified with the method of fractional dispergation of clay in water [21], a modification of the method of Barral et al. [8]. WDC particles dispergate, when soil is carefully mixed with water (1:40) without any mechanical or chemical actions. The clay suspension was removed from a depth of $7 \mathrm{~cm}$ after $7 \mathrm{~h}$ with a siphon. The operation was carried out to a very faint opalescence of the supernatant (at least 20 times). The clay suspension was coagulated with drops of $1 \mathrm{~N} \mathrm{HCl}$ to slightly acidic solution (followed by washing until a negative reaction to $\mathrm{Cl}$ ions) and dried in a water bath. To extract AC fraction, 


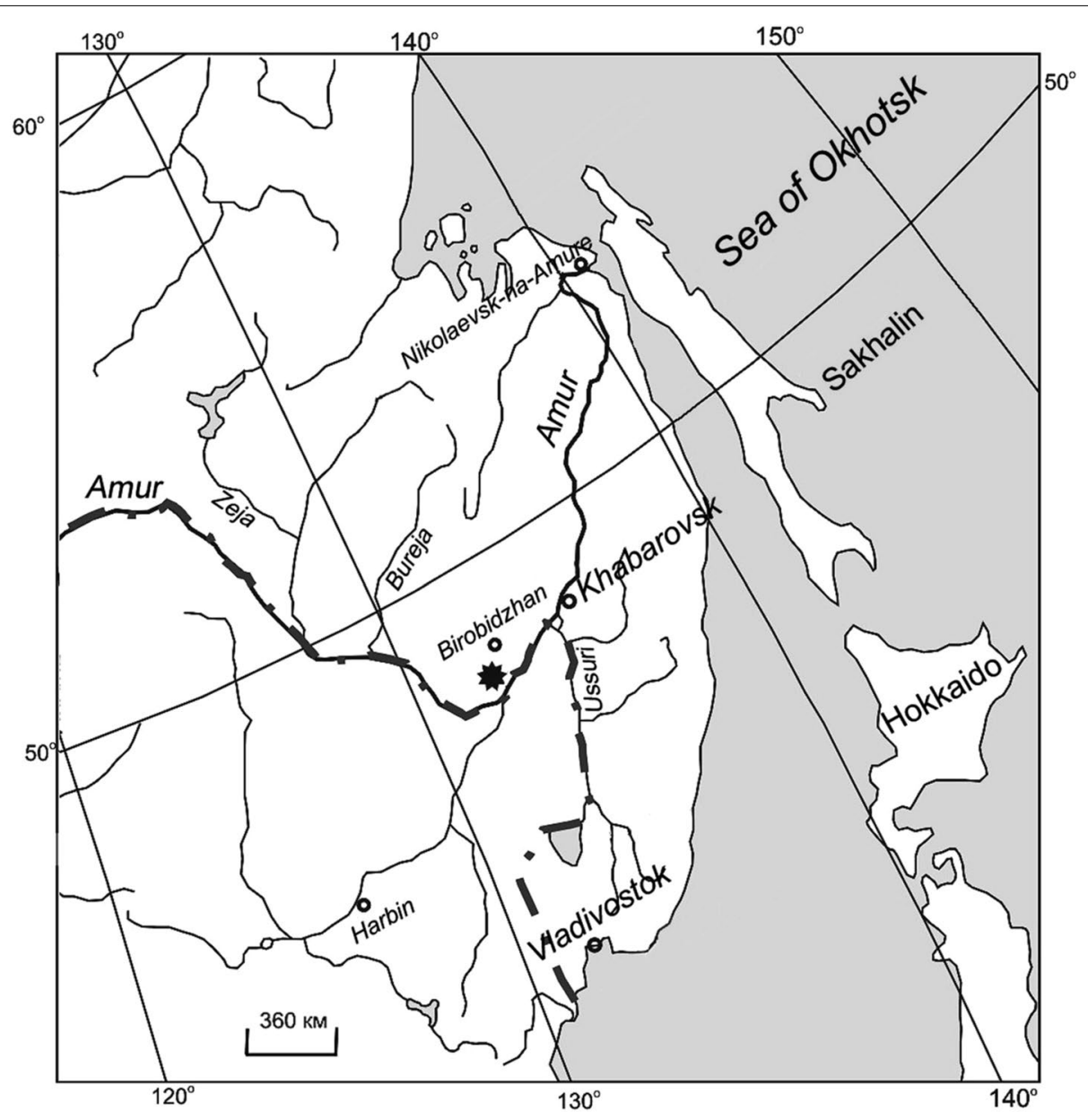

Fig. 1 Location of the study area

Table 1 General characteristics of the soil profile

\begin{tabular}{|c|c|c|c|c|c|c|c|c|}
\hline \multirow{3}{*}{$\begin{array}{l}\text { Horizon, } \\
\text { depth, cm }\end{array}$} & \multirow[t]{3}{*}{$\mathrm{pH}_{\text {water }}$} & \multicolumn{2}{|c|}{ Exchangeable cations } & \multirow{3}{*}{$\begin{array}{l}\text { C-OM } \\
\%\end{array}$} & \multirow[t]{3}{*}{ C-HA } & \multirow[t]{3}{*}{ C-FA } & \multirow[t]{3}{*}{$\mathrm{Fe}_{2} \mathrm{O}_{3}^{\mathrm{a}}$} & \multirow{3}{*}{$\begin{array}{l}\text { Particle content } \\
<0.01 \mathrm{~mm}^{\mathrm{b}}\end{array}$} \\
\hline & & $\mathrm{Ca}^{2+}$ & $\mathrm{Mg}^{2+}$ & & & & & \\
\hline & & \multicolumn{2}{|c|}{$\mathrm{cmol} \mathrm{kg}^{-1}$} & & & & & \\
\hline Ag 0-14 & 5.8 & 16.49 & 4.95 & 4.90 & 1.88 & 1.41 & 1.51 & 58.5 \\
\hline Elcg 22-30 & 5.9 & 11.96 & 7.42 & 1.00 & 0.22 & 0.26 & 2.19 & 60.8 \\
\hline Btg1 65-80 & 6.3 & 17.68 & 9.77 & 0.95 & 0.19 & 0.23 & 1.66 & 79.3 \\
\hline Cg 150-160 & 6.3 & 16.58 & 7.87 & 0.75 & ND & ND & 1.61 & 68.9 \\
\hline
\end{tabular}

C-OM organic matter carbon, C-HA humic acid carbon, C-FA fulvic acid carbon

a $\mathrm{Fe}_{2} \mathrm{O}_{3}$, dithionite-citrate-bicarbonate extracted

b Pipette method

the remaining wet paste-like sample was then kneaded in a weakly alkaline medium $\left(10 \% \mathrm{NH}_{4} \mathrm{OH}\right)$ to destroy aggregates. The other operations were the same as in the first case of WDC extraction.
Further studies included the following procedures. The general physical and chemical properties of soil were studied with conventional methods [22]. The mineralogical composition of WDC and AC was analyzed with 
the universal X-ray diffractometer DRON-2.0. Radiation was $\mathrm{K} \alpha \mathrm{Cu}$, filtered with $\mathrm{Ni}$. Operational mode: tube voltage- $35 \mathrm{kV}$; anode current-12 $\mathrm{mA}$; goniometer rotation speed $-2 \% \mathrm{~min}$. Oriented preparations were used for the X-ray diffractometry. The samples were processed with $30 \% \mathrm{H}_{2} \mathrm{O}_{2}$ to remove organic matter and with the sodium dithionite-citrate-bicarbonate extract following the Mehra and Jackson method [23] to remove free Fe compounds, followed by the saturation with a magnesium cation from $1 \mathrm{~N}$ solution of $\mathrm{MgCl}_{2}$. Specimens were analyzed in an air-dry state $\left(20^{\circ} \mathrm{C}\right)$, after incineration at $550{ }^{\circ} \mathrm{C}$ for $2 \mathrm{~h}$ and saturation with ethylene glycol. The X-ray diffraction patterns were interpreted using the conventional procedures [24]. Semiquantitative estimates of the proportions of different minerals in WDC and $A C$ were obtained using the method of Biscaye [25]. The morphology of WDC and AC particles was studied with a scanning electron microscope EVO $40 \mathrm{HV}$ (Carl Zeiss, Germany). The samples were prepared by suspending in ethanol, drying and Au coating. Magnification was up to 50,000 .

The Turin scheme, modified by Ponomareva (Scheme 1), was applied to estimate the group and fractional composition of humic substances in WDC and AC [26]. By the scheme, humic acids (HA) and fulvic acids (FA) were additionally divided into fractions according to the mode of binding with the mineral matrix of soils. The analysis procedure can be briefly described as follows. At the first stage, HA1 and FA1, free and bound with mobile $\mathrm{Fe}_{2} \mathrm{O}_{3}$ and $\mathrm{Al}_{2} \mathrm{O}_{3}$, are estimated in the alkaline extract $0.1 \mathrm{~N} \mathrm{NaOH}$. HA1 and FA1 are separated after acidification of the extract with $1 \mathrm{~N} \mathrm{H}_{2} \mathrm{SO}_{4}$ to $\mathrm{pH} \sim 1$. At the second stage, a separate portion of the sample is decalcified with $0.1 \mathrm{~N} \mathrm{H}_{2} \mathrm{SO}_{4}$ to estimate FA1a (the most mobile "aggressive" fraction of FA) in the filtrate. Then the alkaline extract $0.1 \mathrm{~N} \mathrm{NaOH}$ is prepared, and four fractions

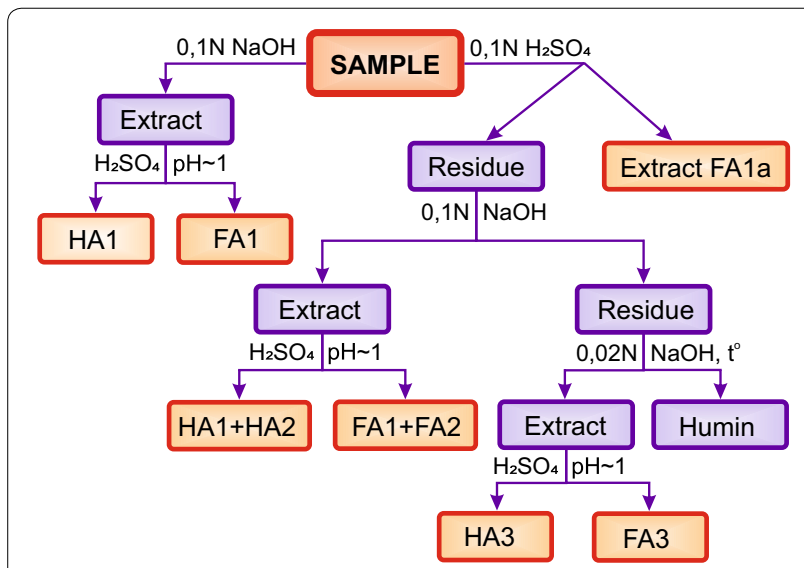

Scheme 1 Fractionation procedure for $\mathrm{HA}$ and FA fractions
(HA1 and FA1, HA2 and FA2) which pass into the solution are analyzed. Based on the difference, we then calculate HA2 and FA2, bound with $\mathrm{Ca}$. The residue is treated with $0.02 \mathrm{~N} \mathrm{NaOH}$, heating on a steam bath for $6 \mathrm{~h}$ to dissolve HA3 and FA3, strongly bound with clay minerals. After the last treatment, the test sample contains humin (non-hydrolyzable residue). Carbon of fractions as well as total carbon were estimated with bichromate oxidation method and measured by spectrophotometer. Non-silicate iron was analyzed with the Mehra and Jackson method in the dithionite-citrate-bicarbonate extraction [23].

The water vapor sorption isotherms (adsorption-desorption cycle) were obtained with a weight method at $25{ }^{\circ} \mathrm{C}$ using an isopiestic instrument [27]. The samples were preliminarily sieved $(<1 \mathrm{~mm})$ and dried at $105^{\circ} \mathrm{C}$. The complete adsorption-desorption isotherms were in the range of relative pressures $p / p_{0}$ from $10^{-3}$ to 1. Each curve was determined from 13 experimental points in spacing of about 0.08 units of $p / p_{0}$ over a sulfuric acid solution. Each sample weighed $1 \mathrm{~g}$, and every measurement was repeated twice. Equilibration time was 1-5 days. The surface area was calculated from the adsorption part of the isotherms with the BET method [28-30] using the equation:

$$
S=a_{\mathrm{m}} N_{\mathrm{A}} w_{0}
$$

where $a_{\mathrm{m}}$ is the adsorption value, corresponding to a monomolecular layer; $N_{\mathrm{A}}$ is the Avogadro's number; $w_{0}$ is the surface area occupied by a water molecule $\left(w_{0}=1.48 \mathrm{~nm}\right)$. The value $a_{\mathrm{m}}$ was calculated with the obtained adsorption isotherms by the BET method.

\section{Results and discussion WDC and AC content in soil}

The composition and distribution of WDC and AC along the meadow podbel profile are shown in Table 2. In the Ag horizon, the WDC content is low $(<2 \%)$, whereas in deeper horizons it increases, reaching maximum at the depths of the soil-forming rock. The increased dispergation of clay in the Btg1 and Cg horizons can be explained by fine-dispersed clay minerals originating from lakealluvial clays; migration of suspended particles to the profile bottom and/or disaggregation due to the gleying process. AC prevails over WDC along the entire profile and most evidently in the humic Ag horizon. The AC distribution along the profile reveals two evident maximums. The first maximum is in the humic Ag horizon, and the second is in the illuvial Btg1horizon.

\section{Humics in WDC and AC}

The organic matter distribution between WDC and AC fractions in the meadow podbel is shown in Table 3. 
Table 2 General characteristics of WDC and AC

\begin{tabular}{llllll}
\hline $\begin{array}{l}\text { Sub } \\
\text { fraction }\end{array}$ & $\begin{array}{l}\text { Horizon, } \\
\text { depth, } \\
\mathbf{c m}\end{array}$ & $\begin{array}{l}\text { Content } \\
\mathbf{( \% )}\end{array}$ & $\mathbf{S}\left(\mathbf{m}^{\mathbf{2}} \mathbf{g}\right)$ & $\mathbf{C - O M}(\%)$ & $\mathrm{Fe}_{\mathbf{2}} \mathbf{O}_{\mathbf{3}}^{\mathbf{a}}(\mathbf{\%})$ \\
\hline WDC & Ag 0-14 & 1.6 & 113.7 & 9.9 & 2.10 \\
& Elcg 22-30 & 9.9 & 125.8 & 3.2 & 1.79 \\
& Btg1 & 19.2 & 225.0 & 1.4 & 2.19 \\
90-100 & & & & \\
AC & Ag 0-14 & 38.0 & 177.5 & 13.3 & 1.99 \\
& Elcg 22-30 & 19.0 & 220.5 & 3.6 & 6.56 \\
& Btg1 & 39.7 & 253.0 & 1.5 & 3.88
\end{tabular}

$S$ surface area, C-OM organic matter carbon

${ }^{\text {a }} \mathrm{Fe}_{2} \mathrm{O}_{3}$, dithionite-citrate-bicarbonate extracted

Calculations were made considering the mass of each clay fraction in soil. All humic and fulvic acids are present in WDC in small quantities, and the content of HA3 and FA3 is especially low (nearly absent). The greatest amount of organic matter is found in AC. Thus, in the humic Ag horizon, about $60 \%$ of total soil humic matter is a part of AC and only $2 \%$ belongs to WDC. The sum of $\mathrm{HA}$ in $\mathrm{AC}$ is 30 times more than in WDC.

The HA1 (free and bound with mobile Fe oxides) prevails in $\mathrm{AC}$ in the $\mathrm{Ag}$ and $\mathrm{Btg} 1$ horizons. The mass portion of the FA1 in AC is less noticeable. The content of humins in WDC is not significant; this fraction is concentrated in the $\mathrm{AC}$ and is 22,13 and $24 \%$ in the $\mathrm{Ag}$, Elcg and Btg1 horizons, respectively, taking into account the mass portion of $\mathrm{AC}$ in each horizon.

\section{Mineralogical composition and morphology of WDC and $A C$ particles}

The obtained X-ray diffraction patterns for the meadow podbel (Fig. 2) illustrate both similarities and differences in the mineralogical composition of WDC and AC. The similarity is that both fractions are characterized by the same set of minerals. In the upper part of the profile (Ag and Elcg horizons), illite noticeably prevails in both fractions (50-67\%); smectite (28-38 \%) and kaolinite (5-12\%) are of subordinate importance. In the lower part of the profile (Btg1 horizon) smectite (54-54 \%) prevails in both cases; illite (36-38 \%) and kaolinite (5-10 \%) are of subordinate importance. Clastic components (fine-dispersed quartz, feldspars, amphiboles) are present in significant amounts in the entire clay profile. Differences between WDC and AC are most notable in the upper part of the profile (Ag and Elcg horizons). Compared with AC, WDC is enriched with clastic components and minerals with rigid structures (illite and kaolinite) and is depleted with minerals with a swelling crystal lattice (smectite). Of clay minerals with rigid structures, chlorite is also present in WDC, but absent in AC. The nature of the peaks of illite and kaolinite on the diffraction patterns (half-width) suggests differences in the preferential size of crystallites of the latter [24]; illite and kaolinite crystallites in WDC are larger than in AC.

Specifics of WDC and AC composition described in the paper clearly correspond to the differentiation of WDC and AC by the peculiarities of particle morphology and in particular the degree and nature of their aggregation (Fig. 3). WDC in the upper part of the profile is represented with non-aggregated relatively coarse particles (Fig. 3a-c), and in the lower part of the profile (Btg1 horizon) with finer particles (lamella) with primary packing "face-to-edge" [31]. AC particles are mostly aggregated with particle packing "face-to-face" (Fig. 3d-f).

\section{Adsorption characteristics and specific surface of WDC and $A C$}

The obtained data (Fig. 4) show significant differences in the hydrosorption capacity of WDC and AC, both at a low relative pressure of water vapor $\left(p / p_{0}\right)$ and at an ultimate uptake $\left(p / p_{\mathrm{s}}\right)$. Important factors able to affect the value of the specific surface of the clay fractions are their clay mineral, HS and free iron contents [32-34].

Table 3 The content of humic fractions in WDC and AC

\begin{tabular}{|c|c|c|c|c|c|c|c|c|c|c|}
\hline \multirow[t]{3}{*}{ Fraction } & \multirow[t]{3}{*}{ Horizon } & \multicolumn{9}{|c|}{$\%$ Soil organic carbon } \\
\hline & & \multicolumn{4}{|c|}{ Humic acids } & \multicolumn{5}{|c|}{ Fulvic acids } \\
\hline & & HA1 & HA2 & HA3 & $\Sigma \mathrm{HA}$ & FA1a & FA1 & FA2 & FA3 & $\Sigma F A$ \\
\hline \multirow[t]{3}{*}{ WDC } & $\mathrm{Ag}$ & 0.76 & 0 & 0.13 & 0.89 & 0.18 & 0.48 & 0.13 & 0.12 & 0.91 \\
\hline & Elcg & 4.04 & 1.94 & 2.02 & 8.00 & 3.16 & 3.08 & 2.79 & 0.64 & 9.67 \\
\hline & Btg1 & 2.01 & 0 & 1.46 & 3.47 & 1.09 & 2.29 & 0.76 & 0.13 & 4.27 \\
\hline \multirow[t]{3}{*}{$A C$} & $\mathrm{Ag}$ & 19.90 & 0 & 6.03 & 25.93 & 3.34 & 9.30 & 1.86 & 5.06 & 19.56 \\
\hline & Elcg & 11.75 & 0 & 6.12 & 17.87 & 8.92 & 6.32 & 10.67 & 0.12 & 26.03 \\
\hline & Btg1 & 17.87 & 0 & 6.92 & 24.79 & 10.13 & 1.33 & 10.82 & 0 & 22.28 \\
\hline
\end{tabular}

$H A 1, H A 2, H A 3$ fractions of humic acids, FA1a, FA1, FA2, FA3 fractions of fulvic acids [26], $\Sigma H A$ sum of humic acid fractions, $\Sigma F A$ sum of fulvic acid fractions 
WDC shows significantly less adsorption capacity than AC. The specific surface of WDC is less than the one of $\mathrm{AC}$ in Ag, Elcg and Btg1 horizons by 64, 95 and $28 \mathrm{~m}^{2} / \mathrm{g}$, respectively, because of the predominance of minerals with rigid structures in its composition. The values of the specific surface of both WDC and AC increase from the upper humic Ag horizon to the bottom of the profile, where they are maximal for both clay factions. The latter is associated with a significant increase of smectite in clay (60\%).

Moreover, the values of the specific surface of WDC and $\mathrm{AC}$ are in strict accordance with the content of humic substances. This correspondence is most evident in the upper Ag horizon, where the humus content in WDC and AC is 9.9 and $13.3 \%$, respectively, for specific surface values of 113.7 and $177.5 \mathrm{~m}^{2} / \mathrm{g}$.

It should be noted that free (non-silicate) iron can affect the specific surface of clay. For instance, the maximum difference in the specific surface for clays $\left(98 \mathrm{~m}^{2} / \mathrm{g}\right)$ was observed in the Elcg horizon, which corresponds to the maximum difference of $5 \%$ in free iron content.

\section{Conclusions}

The present study defined the heterogeneity of the total clay in the periodically overmoistened meadow soil, which is manifested in differences in the composition

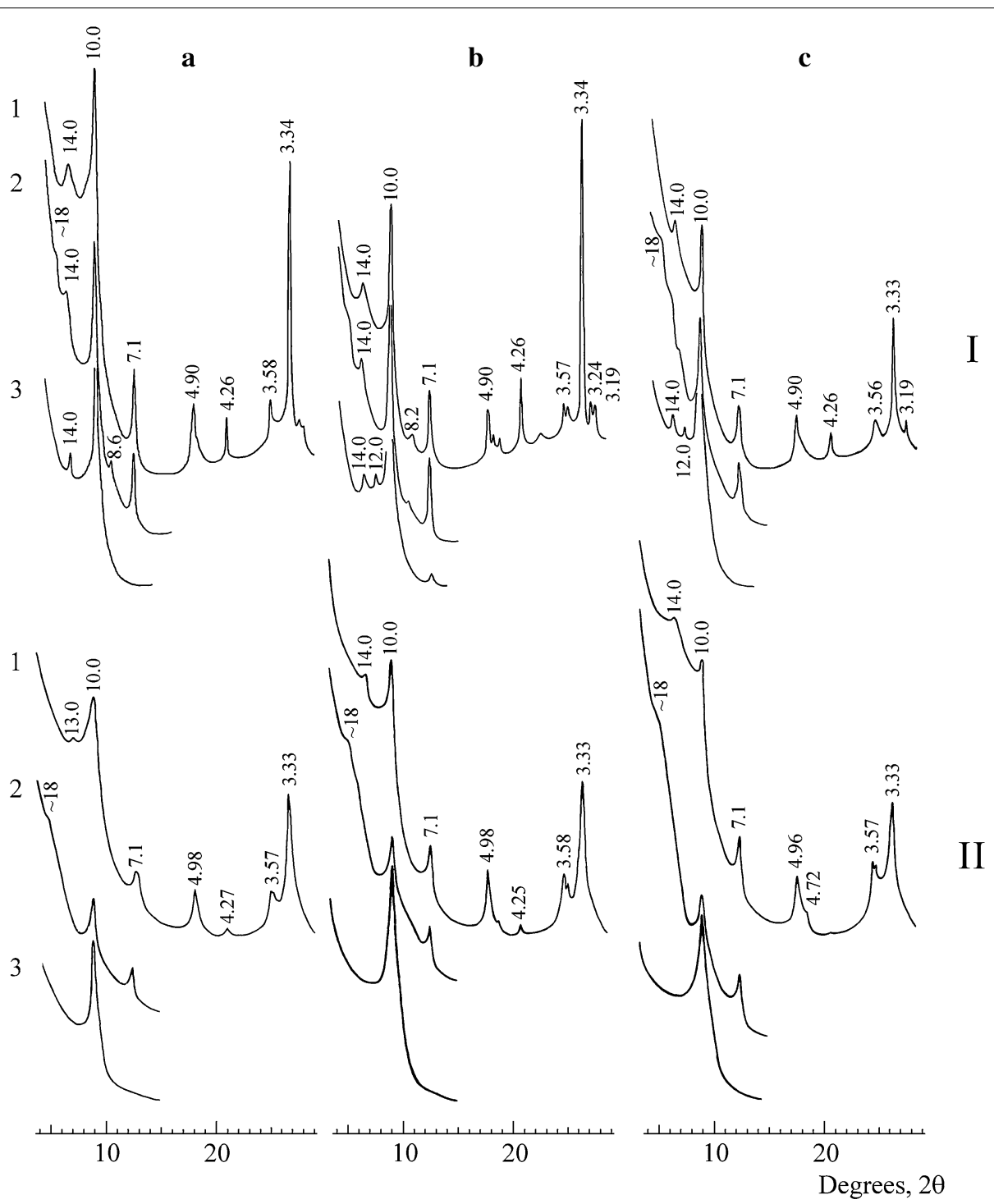

Fig. 2 X-ray diffraction patterns of WDC (I) and AC (II). 1 Air-dry samples; 2 samples after solvation with ethylene glycol; 3 samples after incineration at $550^{\circ} \mathrm{C}$; a Ag horizon; $b$ Elcg horizon; $c$ Btg1 horizon. The peak numbers do not correspond to $2 \Theta$ values, but $d$ spacing values 

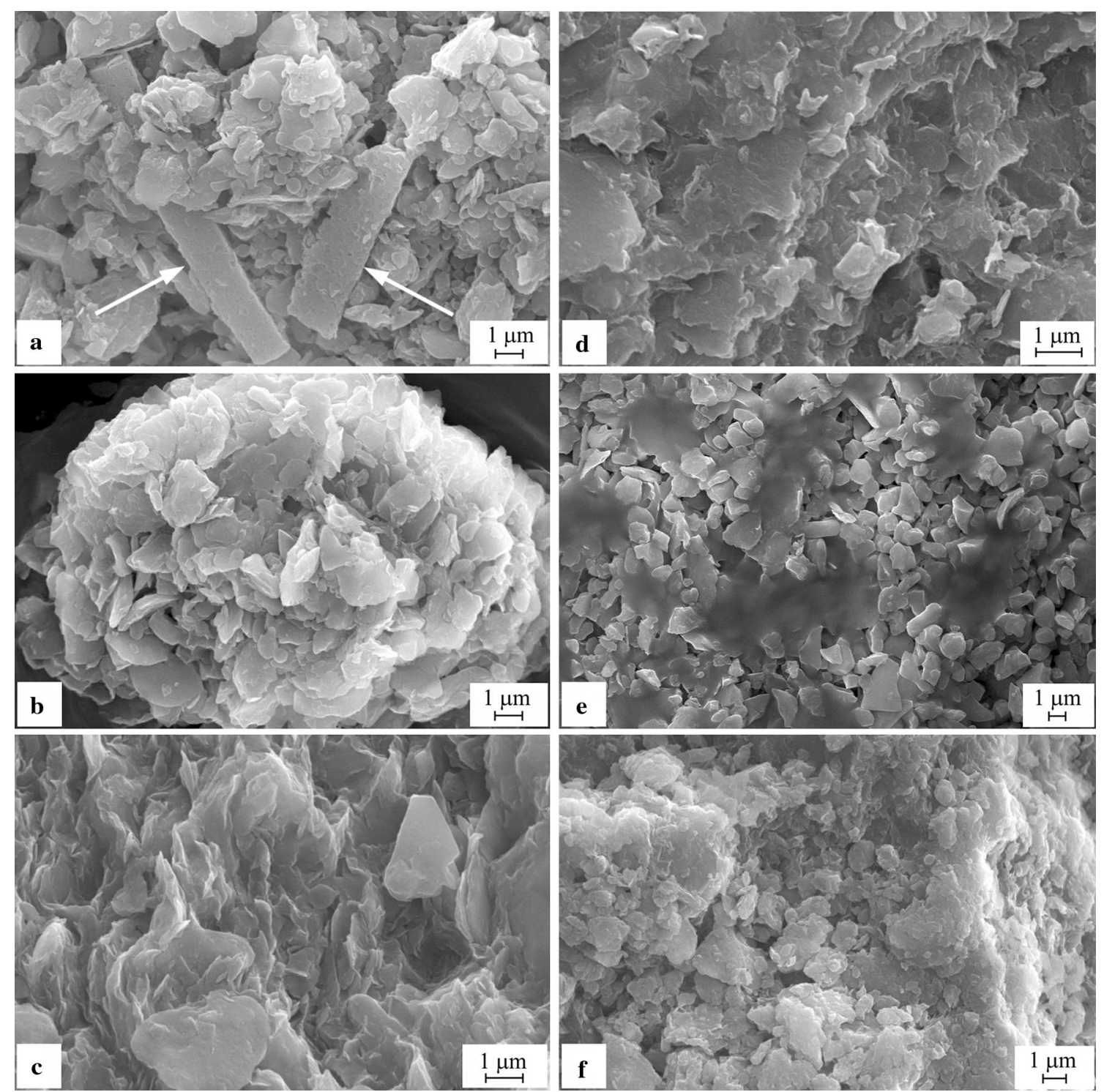

Fig. 3 SEM images of WPC (a-c) and AC (d-f). a-d Ag horizon; b-e Elcg horizon; c-f Btg1 horizon; arrows indicate phytoliths

and properties of two clay fractions-water-dispersible (WDC) and aggregated (AC-a portion of clay that remains after the WDC extraction).

Differences in the mineralogical composition of WDC and $\mathrm{AC}$ are most significant in the upper part of the profile (Ag and Elcg horizons), whereas at the bottom of the profile they are smoothed. Compared to AC, WDC is enriched with clastic components and clay minerals with rigid structures (illite, kaolinite, chlorite) and is detrimental to minerals with a swelling crystal lattice (smectite). It is these components of total clay that form the WDC fraction during soil overmoistening, repeated freezing and thawing.
Organic matter also affects the total clay aggregation and its differentiation to AC and WDC. In the humic horizon with a high content of organic matter $(5 \%)$, most of the clay transforms into an aggregated state. The WDC content does not exceed $2 \%$, while the AC content reaches $38 \%$. In lower horizons, organic matter content decreases, while the WDC content increases to $20 \%$. In all horizons, WDC contains only small amounts of organic substances, since most of the organic matter is concentrated in AC.

Hydrosoption properties of clays change according to their mineralogical composition, content of humus and free iron. In all horizons, AC, compared to WDC, has a 


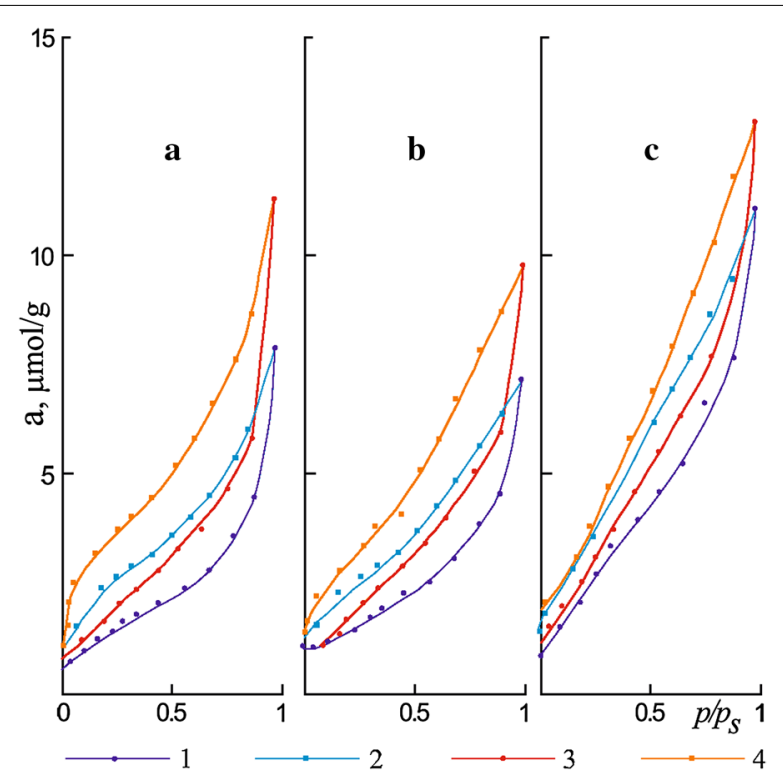

Fig. 4 Isotherms of water vapor sorption of $\operatorname{WPC}(1,2)$ and $A C(3,4)$. 1,3 adsorption; 2, 4 desorption; a Ag horizon; b Elcg horizon; c Btg1 horizon

substantially higher specific surface. However, in both clay categories, the specific surface increases along with depth. In spite of the high content of HS, Ag horizon has the minimum specific surface values due to the amphiphilic character of HS. A significant difference $\left(95 \mathrm{~m}^{2} / \mathrm{g}\right)$ in the specific surface of clays in the Elcg horizon can be explained by the high content of free (non-silicate) iron in AC. The obtained data highlight the importance of studying clay fractions WDC and AC for characterizing the differences in clay aggregation in soils, as well as the importance of humic substances that interact with clay, thus providing different characteristics to the soil matrix.

\section{Authors' contributions}

LAM and GVK contributed equally to this research. Both authors read and approved the final manuscript.

\section{Acknowledgements}

The authors would like to express their gratitude to the two anonymous reviewers for their useful comments and editorial suggestions, which improved the comprehension of the manuscript.

\section{Compliance with ethical guidelines}

\section{Competing interests}

The authors declare that they have no competing interests.

Received: 14 December 2014 Accepted: 25 August 2015 Published online: 08 September 2015

\section{References}

1. Edwards AP, Bremner SA. Microaggregates in soils. J Soil Sci. 1967;18(1):64-73.
2. Van Damm H. Structural hierarchy and molecular accessibility in clayey aggregates. In: Baveye P, Parlange JJ, Stewart BA, editors. Fractals in soil science. Boston, London, New York, Washington: CRC Press; 1998.

3. Kharitonova GV, Matyushkina LA, Manucharov AS, Chernomorchenko NI. Description of isotherms of vapor adsorption by soils. Moscow Univ Soil Sci Bull. 1998;3:42-7.

4. Molina Sabio M, Caturla F, Rodriguez-Reinoso F, Kharitonova GV. Porous structure of sepiolite as deduced from the adsorption of $\mathrm{N}_{2}, \mathrm{CO}_{2}, \mathrm{NH}_{3}$ and $\mathrm{H}_{2} \mathrm{O}$. Microporous Mesoporous Mater. 2001;47:389-96.

5. Oades JM. Soil organic matter and structural stability: mechanisms and implications for management. Plant Soil. 1984;76(1-3):319-37.

6. Piccolo A, Mbagwu J. Role of hydrophobic components of soil organic matter in soil aggregate stability. SSSA J. 1999;63(6):1801-10.

7. Yu Milanovskii E, Shein EV. Functional role of amphiphilic humus compounds in humus. Eurasian Soil Sci. 2002;35:1064-75.

8. Barral MT, Arias M, Guerif J. Effect of iron and organic matter on the porosity and structural stability of soil aggregates. Soil Tillage Res. 1998:46:261-72.

9. Calero N, Barrón V, Torrent J. Water dispersible clay in calcareous soils of southwestern Spain. Catena. 2008;74:22-30.

10. Cañasveras JC, Barrón V, del Campillo MC, Torrent J, Gómez JA. Estimation of aggregate stability indices in Mediterranean soils by diffuse reflectance spectroscopy. Geoderma. 2010;158(1):78-84.

11. Goldberg S, Kapoor BS, Rhoades JD. Effect of aluminum and iron oxides and organic matter on flocculation and dispersion of arid zone soils. Soil Sci. 1990;150:588-93.

12. Mbagwu JSC, Schwertmann U. Some factors affecting clay dispersion and aggregate stability in selected soils of Nigeria. Int Agrophys. 2006:20:23-30

13. Nelson PN, Baldock JA, Oades JM. Change in dispersible clay content, organic carbon content, and electrolyte composition following incubation of sodic soils. Aust J Soil Res. 1998;36:883-97.

14. Oster JD, Shainberg I, Wood JD. Flocculation value and gel structure of sodium/calcium montmorillonite and illite suspension. Soil Sci Soc Am J. 1980:44:955-9.

15. Paradelo R, van Oort F, Chenu C. Water dispersible clay in bare fallow soils after 80 years of continuous fertilizer addition. Geoderma. 2013;200-201:40-4

16. Show JN, Reeves DW, Truman CC. Clay mineralogy and dispersibility of soil and sediment derived from Rhodic Paleudults. Soil Sci. 2003;168:209-17.

17. Matiushkina LA. Distribution of humus substances between clay particles of different peptization level in the meadow soils of the middle Priamurje, Russia. In: Jianming X, Jianjun W, Yan H, editors. Proceedings of the 16th meeting of the international humic substances society: functions of natural organic matter in changing environment. Hangzhou, China; 2013, September 2012, p. 147-9.

18. Stolbovoi V. Soils of Russia: correlated with the revised of the FAO soil map of the world reference base for soil resources. Laxenburg: IIASA; 2000.

19. WRB. World soil resources. Report 103. Rome: FAO; 2006.

20. WRB. World soil resources. Report 106. Rome: FAO; 2014.

21. Gorbunov NI. Mineralogy and physical chemistry of clay minerals. Moscow: Nauka; 1978

22. Van Reeuwik LP, editor. Procedures for soil analysis. Wageningen: International Soil Reference and Information Centre; 2006.

23. Mehra OP, Jackson ML. Iron oxides removal from soils and clays by a dithionite-citrate system buffered with sodium bicarbonate. Clays Clay Miner. 1960;5:317-27.

24. Moore DM, Reynolds RC Jr. X-ray diffraction and the identification and analysis of clay minerals. Oxford: Oxford University Press; 1997.

25. Biscaye PE. Mineralogy and sedimentation of recent deep-sea clay in the Atlantic Ocean and adjacent seas and oceans. Geol Soc Am Bull. 1965;76:803-31.

26. Ponomareva W. Theory of podzolization. Moscow, Leningrad, Israel: Nauka; 1964. Program for scientific translation, Jerusalem; 1969.

27. Kirgintsev AA, Lukyanov AB. A non-vacuum device for examining vapor pressure with the isopiestic method. Russ J Phys Chem A. 1963;37:233-5

28. Brunauer S, Emmett PH, Teller E. Adsorption of gases in multimolecular layers. J Am Chem Soc. 1938;60:309-19. 
29. Brunauer S, Deming LS, Deming WE, Teller E. On a theory of the van der Waals adsorption of gases. J Am Chem Soc. 1940;62:1723-32.

30. Greg S, Sing K. Adsorption surface area and porosity. New York: Academic; 1982.

31. Van Olphen H. An introduction to clay colloid chemistry. New York, London, Sydney, Tokyo: Wiley; 1977.

32. Chizhikova NP, Kharitonova GV, Matyushkina LA, Konovalova NC, Stenina AS. Differentiation of layered silicates and biogenic silica in meadow podbel soils of the central Amur lowland. Eurasian Soil Sci. 2013;46(8):885-96.
33. Farrar DM, Coleman JD. The correlation of surface area with other properties of nineteen British soils. J Soil Sci. 1967;18(1):118-24.

34. Sposito G, Skipper NT, Sutton R, Park S, Soper AK. Surface geochemistry of the clay minerals. Proc Natl Acad Sci USA. 1999;96:3358-64.

\section{Submit your manuscript to a SpringerOpen ${ }^{\odot}$ journal and benefit from:}

- Convenient online submission

- Rigorous peer review

- Immediate publication on acceptance

- Open access: articles freely available online

- High visibility within the field

- Retaining the copyright to your article

Submit your next manuscript at $>$ springeropen.com 